DOI: 10.20472/EFC.2020.013.009

\title{
GEORGE PASMANGIU
}

Bucharest University of Economic Studies, Romania

\section{A RETROSPECTIVE ANALYSIS AND CONSTRUCTION OF A FINANCIAL STABILITY INDEX FOR ROMANIA IN THE 2010S}

\begin{abstract}
:
Often it is implied that financial stability is synonymous with macroeconomic stability, but the two concepts do not reflect the same context. A composite Financial Stability Index (FSI) should accurately represent the components of a financial market. In Romania, the money market along with the capital market, the insurance market, and the private pensions market form the entirety of the financial market. A macroeconomic stability index should represent the overall situation of all economic markets within a country. The main purpose of this paper is to design a better, more suitable aggregate index that best describes the notion of financial stability. The composite Financial Stability Index signals through its components, the general financial conditions of a nation's economy. This paper explores the constituent economic variables for Romania that would lead to the completion of an improved aggregate index and the evolution of said index. Romania entered the last decade in the middle of a financial crisis that delayed its economic development and the accession to the euro area. To determine the trend of the financial market in Romania during the last decade, a VAR model and Principal Component Analysis (PCA) are used to conduct an econometric analysis for the 2010-2019 period. The results of this study demonstrate that, even though the Romanian financial market was weakened from the beginning of the analyzed period, it gradually managed to reach financial stability in the more recent years, although residual instability still remains a possibility in the near future. The modeled econometric data was collected from various international and national databases, such as Thomson Reuters Eikon platform, The National Bank of Romania (NBR) database, and The Financial Supervisory Authority (ASF) reports.
\end{abstract}

\section{Keywords:}

capital market, financial market, financial stability index, money market, VAR model

JEL Classification: C32, C38, E44 


\section{Introduction}

Among all European Union states, the situation of Romania is rather interesting from both socialeconomic and financial points of view. Characterized by nothing other than constant instability after the fall of communist regime, the Romanian economy has just begun to recover from darker and restrictive periods, during the last decade, by allowing the entirety of the financial market to grow steadily. Such growth in the financial market can be traced back towards many foreign direct investments that have reshaped the majority of the business environment. Up until the emergence of a global financial crisis of 2007-2008, that would also eventually affect Romanian businesses in the following years, most experts would have agree today that Romania entered a short-lived economic boom during the period 2005-2006, which acted as a catalyst for attracting new foreign investors. Economic literature teaches us that the financial aspect of everyday life is just one particular and targeted side of the economic environment. Therefore, to be able to explain or to predict financial inconsistencies or deficiencies would be all the more difficult to conceptualize when using quantifiable variables that merely describe general economic trends. It be would harder to pinpoint a cause for financial instability or equilibrium in the absence of specifically targeted financial variables that would better describe reality. Unlike macro-prudential composite indicators, an aggregate financial stability index should be oriented towards attributes that solely reflect the activity performances of notable financial entities, viewed as collective subdivisions of the financial markets. Such indicators that manage to characterize fluctuating values by economic agent typology are provided by countryspecific financial authorities that oversee, authorizes, issue legislations and sanction different financial practices of banks, capital markets, insurance companies, financial intermediaries, such as insurance brokers, and privately managed funds.

This paper intends to incorporate the above stated motivation into analyzing and constructing a different type of composite financial indicator. The following part of the paper will introduce notable studies that have elaborated other versions of this notion. During the third part, the methodology of work is presented by describing the logic behind each econometric technique and model used, mainly the Principal Component Analysis and the VAR model. All data has a quarterly frequency and referes to the period 2010-2019. The fourth part showcases the results of the applied econometric analysis. The final parts of the paper consist in concluding remarks and literature references.

\section{The Path Towards A Financial Stability Index}

To have a better understanding of the subject, first we must observe the work of local researchers in the field. Albulescu (2008) presents an Aggregate Financial Stability Index that 
strongly relies on the concept of a composite index composed of indicators divided and categorized after three main characteristics: financial development, financial vulnerability, and financial soundness. While the paper does stipulate that the Romanian financial market has three main components ( the capital market, the money market and the insurance market), the selected indicators are mainly designed to represent the features of the money market, duet to the fact that it is the most prominent market in Romania, before and after becoming a state member of the European Union. The weighted average applied to the components is influenced by an additional ranking, a personal economic judgement that puts financial development at the top. The resulted index is studied from the perspective of its standard deviation over the course several quarterly periods ranging from 1999 towards 2006. At the beginning of the analyzed period, the spike of the index is rather high due to the already known banking crisis that occurred during 1998-1999, but later it is improving with the exception of minor burst in 2005 regarding a sudden expansion of loans granted, which leads to short lived economic boom. As the author states, this method is efficient through its simplicity, transparency and by using only accessible, relevant data. Using a different approach is Stancu (2017), which uses a VAR model in order to study and estimate the correlation between the financial variables and the real economy. In theory, the development of a financial stability index (FSI) should be based on weighted financial variables, as components. The selected variables for this study are a mixture of economic variables (consumer price index, budget deficit, net export, and real GDP) and financial variables pertaining to the three main aspects of the financial market. In his study, the Romanian and Euro interbank Offered Rate abbreviated as ROBOR and EURIBOR, the real effective exchange rate or REER define the activity of money market. VIX volatility index and local stock index BET are the variables most representative for the capital market. The insurance market is portrayed by the number of gross premiums subscribed. Afterwards, the paper focuses on the results that prove the existence of a significant correlation between FSI and GDP and a strong causality link in times of financial crisis. Also using the VAR methodology is Manolescu and Manolescu (2017), who recreate a similar study, as a solution to the need of anticipation of financial instability. The paper itself focuses on the many definitions of financial stability and instability. Most points of view lean towards the importance of the banking system. The opinion the NBR (National Bank of Romania) Governor is that stability can divide into two different meanings, a wider one and a limited meaning. A limited meaning of financial stability implies under control price indexes, while the broader meaning tends to refer attracting funds, more investments and to efficiently allocate the accumulated resources so much that a financial shock could not produce sufficient damage. In addition to the variables used by Stancu (2017), the work performed in this publication also utilizes microeconomic variables such as profitability rates, bank to assets ratios, percentages of non-performing loans and a leverage rate. After a two-quarter period, the answers of the impulse-response functions between GDP and every 
other variable serve as calculated portions for the final index. The end result is a close correlation between FSI and nominal GDP. Vintu and Negotei (2018) have developed also with quarterly data collected from the European Central Bank (ECB), for Euro Area, a composite financial stability index (CFSI) that responded to the fluctuations in data during unstable periods of time. For this econometric opportunity, a Monte Carlo simulation was implemented for a methodology similar the early warning systems (EWS) and stress-testing techniques, but with the advantage of time comparisons provided by the time series data contained in the index. The index is composed of 4 subcategories for 25 indices that describe the activity of the external macroeconomic sector, domestic macroeconomic sector, financial sector, and global economy sector. Thus, the weights of the components are equally assigned and the values are normalized, ranging from 0 to 1.The results analyze the period 1998-2012 and correlate with instability caused by the credit collapse of the U.S and global banking system, but also demonstrate a recent improvement.

Looking from international point of view, many researchers worldwide have also attempted to quantify and centralize the degree of financial instability. Moris (2010) develops for Jamaica an aggregate financial stability index in same manner as Albulescu (2008), by using 4 classes of indices: financial development, vulnerability, soundness and a new world economic conditions composite index, most variables being macroeconomic either bank oriented. The data was normalized with regard to the minimum and maximum values of each series, the weight being thus equally applied. The evolution of the final index revealed that in Jamaica, financial distress has been present in the late 1990s, around the year 2003 and after the emergence of lobal financial crisis in 2008. Afterwards, an ordinary least squares model is used to determine negative relationship between yield on 6-month Treasury bill and a contradictory link with the growth in money supply (M2). This proves that a variety of methods and models, depending on their accuracy, could be used to detect the levels of financial equilibrium. For the Pakistani national economy, Babar, Latief, Ashraf and Nawaz (2019) have finalized a composite index, based on three categories of indices, and category had produced a composite index through a variance equal-weighted method, a linear probability model and a logit model. The majority of variables are monetary and bank related. Their resulted index shows disturbances in multiple years (2001, 2005, 2006, 2007). Arzamasov and Penikads (2014) apply the Principal Component Analysis (PCA) on an initial selection of 16 Financial Soundness Indicators. Their data has a quarterly frequency and is also computed through regression models and other hybrid methods. The results of each method do not present significant differences. Morales and Estrada (2010) construct a composite stress index as an alternative to financial soundness indexes or VAR estimated financial indexes. The characteristics of this index rely on profitability, liquidity and default probabilities. Their results seem to effectively indicate the stress level of the Colombian financial system. Ultimately, Geršl and Heřmánek (2007) attempt to construct an 
aggregate financial stability indicator by combining IMF Financial Soundness Indicators and European Central Bank macro-prudential indicators for multiple European and non- European countries. A particular case in their study is the financial system of the Czech Republic, for which a specialized financial stability index is constructed, namely the Banking Stability Index, adjust to exclusive banking related variables that concentrate on capital adequacy, asset quality, profitability, liquidity, interest rate risk and foreign exchange risk.

After examining the specialized economic literature, the initial set of variables for this study consists of exclusive financial variables, that quantify either the added value obtained through financial operations, either reflect the market intensity. These variables are the BET Index, the ROBOR index at a 3 month maturity, the degree of intermediation in insurance and return on equity rate for privately managed pension funds for pillar II pensions.

\section{Methodology}

\subsection{Econometric techniques performed}

When constructing the financial stability index, most researchers will follow three major steps as follows: first by selecting the adequate individual indicators, second by applying the normalization method for the input data and last, by constructing the index with a reasonable weighting methodology.

Before applying the necessary calculus, data must be analyzed in order to determine its efficiency. The analysis that can determine whether said dataset signals desirable, relevant, and noiseless information is the Principal Component Analysis. The Principal component analysis (PCA) is developed specifically to identify and to extract the most relevant variables from a given set of proposed variables, that are uncorrelated, by reducing the dimensionality of the system variable's matrix. To put it in other words, by conducting the PCA analysis, it will guarantee that the proposed variables, although they relate to a common field of interest, are not codependent, therefore the level of redundancy will be at minimum.

By starting with an initial matrix $X$, which incorporates all original system variables, the procedure will produce a transformed matrix, with a new set of variables, assumed to be all uncorrelated. The scope is to identify, through total system variation decomposition, all unnecessary correlations and reduce the number of variables, while still retaining the majority of important information.

$\sum_{X}=E\left(X^{T} X^{1}\right)$ 
to be noted as the matrix form of a squared symmetric matrix that would follow the next relationship:

Total system variation $=\sum$ variation terms $+\sum$ covariation terms

where $\sum$ covariation terms is ultimately equal to 0 . This procedure can be included in the first step, of selecting adequate working variables.

All econometric methods and techniques employed are performed with the usage of the statistical software EViews. After the implementation of PCA, the raw data sets are seasonally adjusted. The seasonally adjusted series are later normalized, a practice often applied when generating complex econometric models, such as the Vector Autoregressive (VAR) models. This specific type of regression is much more complex than Ordinary Least Squares (OLS) models because it allows far more investigations regarding causality, correlations, variances and covariances between variables. VAR models are used to determine the interdependencies among multiple time series, cross-sectional series, or panel series. One definitive characteristic of the VAR models is that at least one of the variables is explained through its own historical values, while the other variables are simply independent and presumed uncorrelated variables. Many tests can be performed within the VAR model output, but only one test can be of use in constructing a composite index. The impulse-response test can be utilized to obtain a response coefficient between a dependent variable and multiple independent explanatory variables. The resulted coefficients will then be used to a composite weighted index for the financial market of Romania.

\subsection{Description of selected variables}

The working variables which I will employ in the VAR model are the following: ROBOR_3M for the money market, BET index for the capital market, Insurance intermediation degree ( INTERMEDIATE_DGRE as percentage) for the insurance market and the return on equity (PRIVATE_PENSION_FUND_ROE) from pillar II private pension as proxy for the private pension market. All variables introduced are time-series with a quarterly frequency and chosen proxies for each subdivision of the financial market based on their methodology of construction. The Romanian Interbank Offer Rate or ROBOR is an established benchmark interest rate for loans granted by one bank to another Romanian banks in the form of deposits. The interest rate is made solely for domestic interbank operations and presents different rates at a different maturity. The maturity fixated here is at 3 months and it was selected in accordance with the quarterly frequency of data. All ROBOR and EURIBOR values are determined by Thomson Reuters, under the supervision of the National Romanian Bank that oversees and manages all 
aspects regarding the functionality of the Romanian banking system. All raw data related to ROBOR 3M was extracted from the NBR database. Thus, its value represents the added value created by the functionality of the banking system as a whole.

The BET (Bucharest Exchange Trading) index is a weighted composite index composed of the market price per share of the most traded companies on the Romanian capital market. The entity that establishes the BET index values daily is BVB (Bucharest Stock Exchange), which encompasses both domestic traded companies and international entities or groups. Basically, the combined added market value of all shares contained within the index, on top of their respective accounting value, represents the most accurate representation of performance levels exhibited by the afore mentioned capital market.

The return on equity from pillar II private pension funds is in actuality a weighted average of the rentability rate obtained across all available pension funds for this pillar in Romania. The pillar II pension funds in Romania are statutory, mandatory and automatically withdrawn portions from employee incomes that serve as a secondary pension source for each said employee, since it has been well determined that the pillar I pensions in Romania, those that regarded as a limit age compensations for work rendered during active lifetime, are mostly no longer capable of sustaining financially a decent retirement plan for elderly citizens. This return on interest rate will mark the essence of the private pensions funds submarket, that of generating profit and added value back to its contributors.

The degree of insurance intermediation represents the ratio between the number of intermediated insurance premiums and the number of insurance premiums subscribed. Usually, insurance contracts are not performed directly between parties and are intermediated by several various economic agents named insurance brokers. Insurance broker operations represent the majority of cases, most of which high valued contracts. Therefore, the degree of insurance intermediation best describes the ability of the insurance market to generate more money.

The last variable is the nominal GDP, with seasonally adjusted data at a quarterly frequency. The Gross Domestic Product is used as benchmark variable to determine the impact of financial variables in the national economy, from the perspective of a market values, since nominal GDP represents the market value of all final goods and servies from a nation, during a year.

All quarterly and monthly data sets, in econometric modelling, are seasonally adjusted to eliminate the cyclical movements and the expose the fundamental trend of the time series.

The analyzed period is between the years 2010-2019 and all data refer to the the Romanian national economy, all values and rates are expressed in RON or with reference to RON (national currency of Romania). 


\section{Results}

Construct an improved composite financial index, the quality of data, or rather of information, is a fundamental objective. To better the relevance of the utilized data, the calculus must express in matrix form, with the aid of eigenvectors and eigenvalues. The Principal Component Analysis (PCA) is the most appropriate method of analyzing such data.

Certain necessary steps need to be performed in order the complete the Principal Component Analysis, as follows:

- Summary and description of the analysed data set

- Extraction of principal directions

- Determine the percentage of which information can be explained by other principal directions

- Determine the contribution of each variable to each principal direction

- Dimensionality reduction of variables

- Determine the level of importance of each correlation between variables

- Identify the correlations between corelated observations and variables.

The analysis will be performed on all variables, except nominal GDP, for reasons that represent the scope of this paper, to construct a better financial index, one that does not directly rely on macroeconomic indicators, such as GDP. Except for BET, all other 3 variables are expressed in percentages.

\subsection{Descriptive statistics}

All selected variables are extracted from various Romanian institutions and financial entities that oversee, regulate and manage all financial operations within the nation. From the descriptive statistics, I can be noticed that the BET index has an average value of 6711,710 RON ( national currency of Romania), ranging from a minimum of 4327.130 to a maximum of 9977,300 . For ROBOR 3M the average value is about $3,36 \%$ for the interbanking operations, although the cost of loaning has reach $7,16 \%$ for the analyzed period. On the other hand, the return rate on pension funds reveals higher levels, with an average of 7,65 \% rentability and a maximum of $15,86 \%$. The average intermediation degree in insurance is above $50 \%$ which is consistent with economic reasoning that most subscribed insurance premiums are mediated by broker firms. 
Table1. Descriptive statistics of proposed variables

\begin{tabular}{l|cccc}
\multicolumn{1}{l}{ Variables } & BET & ROBOR 3M & $\begin{array}{c}\text { Intermediation } \\
\text { degree }\end{array}$ & $\begin{array}{c}\text { ROE Private } \\
\text { Pension Fund }\end{array}$ \\
Min & 4327.130 & 0.690000 & 33.70000 & 2.720400 \\
Max & 9977.300 & 7.160000 & 66.34000 & 15.86870 \\
Mean & 6711.710 & 3.362250 & 53.58075 & 7.651238 \\
Std. Dev. & 1431.867 & 1.986886 & 11.16826 & 3.823769 \\
Obs. & 40 & 40 & 40 & 40
\end{tabular}

Source: Author's own calculations using EViews

Also, by using the graphics for each variable, the evolutionary trend can be better observed during the analyzed period. To be noted that the BET index starts with a low value at the beginning of 2010q1, around 6000 RON, drops even lower in $2011 q 3$ and afterward rises until the end of $2019 q 4$, up to its maximum price, thus confirming that the Romanian capital market has been expanding its trade, by amassing more and more publicly listed and successful private companies, and is recovering from last decade's financial crisis.

If we observe the dynamics of the Romanian interbank rate ROBOR 3M, the graphic shows a starting value of $5,7 \%$ and an early sudden increase at its maximum level of $7,2 \%$ in the next quarter. Later, it reaches a minimum value in $2016 q 3$, but at the end of $2019 q 4$, it stabilizes at a rate of around $3 \%$, which is an acceptable level of interest in terms of macroeconomic stability. This signifies that, while the at beginning of the study the interest rate was higher due to macroeconomic instability and a certain blockage of interbank loans, ROBOR 3M has reached visible stability on short term operations. Since the index is a benchmark value, it is implied that all other banks follow its trend, at least with low variability between entities.

The figure for intermediate degree of subscribed insurance premiums shows a fast growth in the number of insurance broker companies that render such services, as well as an increase in the volume of their business, an increasing number of high valued insurance contract that needed intermediation. This fact can be well noted, in 2010q1 the degree of intermediation was $34 \%$, as time flows its percentage elevates towards an early peak in $2016 q 4$ at $66 \%$, which repeats at the end of 2019. For most of the selected variables, the year 2016 is turning point for the internal economy for the best, except for level of rentability of private pension funds. 
Figure 1. Evolutionary trend of proposed time-series variables
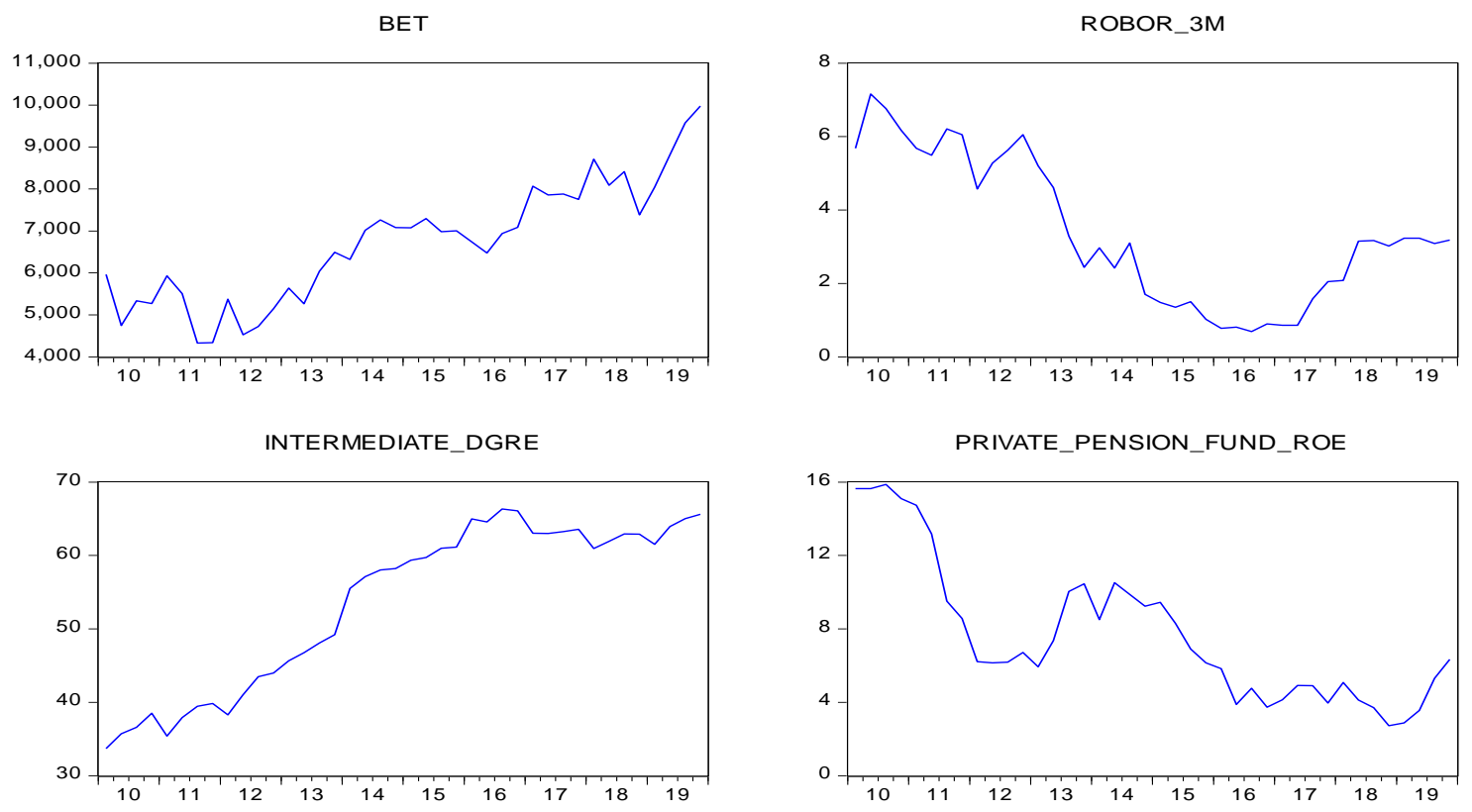

Source: Author's own calculations using EViews

When looking at the at Pilar II of private pension funds, a different scenario can be distinguished, one that states a downfall of the private pension market, at least for this specific pillar. At a rentability rate of approximate $15 \%$, the privately administrated pension funds seem to be very promising at the beginning of the analyzed period, with known risks involved, but their rentability slowly decreases over time. In 2016, the variable reaches a low point of 3,9\%, and in 2018 it declines to a new minimum threshold of $2,7 \%$. One likely and rational explanation, supported by public information, is that financial entities, whether banking institutions or non-banking financial institutions, would prefer to keep the attached risk of such equities at a minimum in fear of losing their contributors. The Romanian legislation is in a constant fluctuation regarding pillar I pensions, so the best solution would be preserving as much as possible this type of compulsorily constituted funds. The best method of preservation is to minimize exposure towards high risks, resulting in low earnings.

\subsection{The correlation matrix}

By applying a variance-covariance analysis with a focus on the correlation relationship between variables, a correlation matrix is obtained in EViews. The variance decomposition part of study is embedded in the PCA output. Evidence resulted indicates that BET is highly correlated with degree of intermediation in insurance at $83 \%$ and is mostly negatively correlated with ROBOR_3M and PRIVATE_PENSION_FUND_ROE. An increase in insurance broker activity can reflect a rising number of publicly listed insurance broker companies on the Bucharest Stock 
Exchange. In fact, only one insurance broker company was listed in 2016, Transilvania Insurance Broker S.A. The negative correlation between the proxies of the capital market and private pension market is undoubtedly confirmed by their descriptive graphics, BET index is rising, while PRIVATE_PENSION_FUND_ROE decreases. Both variables rely on financial assets and as I mentioned, the private pension market tends to not invest in high-risk assets, thus lowering the ROE rate more and more. On the opposite side, BET heavily relies on highrisk financial risks since they add more value.

\section{Table. 2. Correlation matrix}

\begin{tabular}{|c|c|c|c|c|}
\hline & BET & ROBOR_3M & $\begin{array}{l}\text { INTERMEDIATE } \\
\text { DGRE }\end{array}$ & $\begin{array}{c}\text { PRIVATE_PENSION } \\
\text { FUND_ROE }\end{array}$ \\
\hline BET & 1.000000 & & & \\
\hline ROBOR_3M & -0.661532 & 1.000000 & & \\
\hline INTERMEDIATE_DGRE & 0.830877 & -0.887479 & 1.000000 & \\
\hline $\begin{array}{c}\text { PRIVATE_PENSION_FUND } \\
\text { ROE }\end{array}$ & -0.526242 & 0.595434 & -0.751137 & 1.000000 \\
\hline
\end{tabular}

Source: Author's own calculations using EViews

Another negative relationship occurs between ROBOR_3M and INTERMEDIATE_DGRE. Insurance companies that sell their insurance products through direct channels are only one of two alternatives, the other alternative being insurance brokers. Only insurance companies have a strong business relationship, by means of promoting their insurance packages through banking sales channels. This type of cooperation is called insurance banking and so is the case of Romanian banking and insurance environment. Broker companies are just starting to develop in this part of Europe. Therefore, it stands to reason that the welfare of the banking system is in contradiction with the welfare of insurance broker companies, for now.

The precautionary behavior of the private pension funds would allow a positive correlation between ROBOR_3M and the ROE of private pensions. Stable interbank loaning is a constant assurance for private funds that do not want risk, it signifies a stable source of deposits that can sustain functional market transactions. But paradoxically, BET displays a rather strong negative link with the banking proxy variable. Only a few publicly listed banks are within BET's composition and its is most likely possible that the majority of banks practice issuing bonds. Bonds do not offer high earnings, nor it is considered a risky financial asset, in opposition towards the high-valued components of the BER index. Lastly, the negative coefficient that connect PRIVATE_PENSION_FUND_ROE and INTERMEDIATE DGRE marks their trend pattern on the Romanian capital market. 


\subsection{Principal Components Analysis Output}

As it was mentioned beforehand, the PCA analysis involves the use variables calculated in matrix form, by using concepts such as eigenvalues and eigenvectors. Eigenvectors represent linear transformations of the original variables' matrix that can change the magnitude of a matrix transformation but cannot change its direction. Every eigenvector has attached a corresponding eigenvalue, resulted from the matrix transformation. Therefore, the eigenvalue equals the quantified difference in magnitude. Eigenvectors also carry the quantifiable and weighted contributions of each original system variable to the general directionality of said vector. The directions of eigenvectors, known in statistical oriented literature as principal directions. The term" principal directions" are not be confused with the concept of" principal components". Principal components, or scores, are considered to be the projections of the initial set of variables on the newly obtained principal direction. By consequence, when conducting variance decomposition, it is noted that the variance of each principal component is equal to the eigenvalue associated with its corresponding principal directions. These transformations are meant to reduce statistical background noise and redundancy of information that could reside in unnecessary correlated variables. Ultimately, these variables are to be eliminated from the initial set variables. In short terms, the Principal Component Analysis only retains variables that are relevant and mutually uncorrelated. In EViews, two different Principal Component Analysis output tables can be generated, as follows:

Table.3. Principal Components Analysis Output for Eigenvalues

\begin{tabular}{|c|r|r|r|r|r|}
\hline \multicolumn{7}{|c|}{ Principal Components Analysis } \\
\hline \multicolumn{7}{|c|}{ Eigenvalues: (Sum = 4, Average = 1) } \\
\hline Number & Value & Difference & Proportion & Cumulative & Cumulative \\
\hline 1 & 3.142739 & 2.657232 & 0.7857 & 3.142739 & 0.7857 \\
\hline 2 & 0.485507 & 0.156575 & 0.1214 & 3.628246 & 0.9071 \\
\hline 3 & 0.328933 & 0.286111 & 0.0822 & 3.957179 & 0.9893 \\
\hline 4 & 0.042821 & --- & 0.0107 & 4.000000 & 1.0000 \\
\hline
\end{tabular}

Source: Author's own calculations using EViews 
The first PCA table is a summary regarding eigenvalues information where they are arranged in order of importance (of how principal they are). The proportion section measures the extent to which all gathered information is explained by each principal direction. These results state that the first principal direction explains approximately $78,6 \%$ of the information contained in the correlation matrix, the next principal direction explains $12,14 \%$ and so on. The first two principal direction cover for more than $90 \%$ of all available information. Based on the output, there is a need for dimension reduction, which means that the total number available variables for computation is reduced to only two variables.

Table.4. Principal Components Analysis Output for Eigenvectors

\begin{tabular}{|c|r|r|r|r|r|}
\hline \multicolumn{7}{|c|}{ Eigenvectors (loadings): } \\
\hline Variable & PC 1 & PC 2 & PC 3 & PC 4 & \\
\hline BET & 0.482138 & 0.532001 & 0.623674 & -0.309108 & \\
\hline $\begin{array}{c}\text { ROBOR_3M } \\
\text { INTERMEDIATE_D } \\
\text { GRE }\end{array}$ & -0.504514 & -0.166448 & 0.738116 & 0.415866 & \\
\hline $\begin{array}{c}\text { PRIVATE_PENSIO } \\
\text { N_FUND_ROE }\end{array}$ & -0.453070 & 0.827875 & -0.246919 & 0.826514 & \\
\hline
\end{tabular}

Source: Author's own calculations using EViews

The econometric theory states that all eigenvectors have length unity, meaning that for each principal direction, the sum of contribution from all four variables should amass up to $1(100 \%)$. For the first eigenvector, [ 0.482138, - 0.504514,0.554739, -0.453070$]^{\top}$, the BET index accounts for $0,482138^{2} \times 100 \%=0,232457 \%$ of overall direction length. ROBOR_3M accounts for $-0.504514^{2} \times 100 \%=0,254534 \%$ of principal direction 1 . INTERMEDIATE_DGRE accounts for $0.554739^{2} \times 100 \%=0,307735 \%$ of principal direction 1. And finally, PRIVATE_PENSION_FUND_ROE accounts for $-0.453070^{2} \times 100 \%=0,205272$. It can be observed that the least important variable in the first principal direction is PRIVATE_PENSION_FUND_ROE, while the most important is ROBOR_3M, but at the same neither variable dominates in any way.

For the second principal direction, [ 0.532001, $-0.166448,0.062393,0.827875]^{\top}$, the BET index accounts for $0.532001^{2} \times 100 \%=0,283025 \%$ of overall direction length. ROBOR_3M accounts 
for $-0.166448^{2} \times 100 \%=0,027704 \%$ of principal direction 1 . INTERMEDIATE_DGRE accounts for $0.062393^{2} \times 100 \%=0,00389 \%$ of principal direction 1. And finally, PRIVATE_PENSION_FUND_ROE accounts for $0.827875^{2} \times 100 \%=0,685377 \%$. It can be observed that the least important variable in the second principal direction is INTERMEDIATE_DGRE, while the most important is PRIVATE_PENSION_FUND_ROE dominates with almost $70 \%$. But the process of elimination in the case of principal directions has only scope, that of feature extraction, not reduction of dimensionality. Thus, the eigenvalues table will provide the functional number of working variables, in order of importance, which are the proxy variables for the money market and capital market, in accordance with economic literature and the effective reality of collected data.

\subsection{Normalization}

The second step of the financial index construction process represents normalization. Normalization is practically utilized to flatten, to standardize the values of all selected indicators. In EViews, the input data of a time-series variable can be easily transformed from raw values to natural logarithms. This way, the mathematical calculus will return with less complicated and incompatible numbers.

\subsection{VAR model output}

To create a starting point of view, the descriptive statistics will include the benchmark selected component variable, the nominal GDP, presented in presented in Table 1. Before normalization, all values have already been converted from raw data to seasonally adjusted data sets.

Using the nominal GDP as a benchmark reference variable for national internal value, a Vector Autoregressive (VAR) model is generated with nominal GDP as a dependent variable. The rest of the variables, selected through Principal Component Analysis (PCA), are independent, explanatory variables that can measure each partial contribution to GDP's overall evolutionary trend with regard to restrictions concerning covariances and individual uncorrelated variances.

\section{Table 5. Descriptive statistics of seasonally adjusted raw data}

\begin{tabular}{|c|c|c|c|c|c|}
\hline Variables & $B E T$ & ROBOR $3 \mathrm{M}$ & $\begin{array}{c}\text { Intermediation } \\
\text { degree }\end{array}$ & $\begin{array}{l}\text { ROE Private } \\
\text { Pension Fund }\end{array}$ & $G D P$ \\
\hline Min & 4411.078 & 0.660544 & 34.55710 & 2.800109 & 101572.9 \\
\hline Max & 10497.01 & 7.120162 & 65.83777 & 16.43136 & 320373.1 \\
\hline
\end{tabular}


Mean

Std. Dev.

Obs.

$$
6712.322
$$

1444.924

40
3.364260

1.986982

40
53.56939

11.11350

40
7.677221

3.823769

40
183179.6

52359.79

Source: Author's own calculations using EViews

The descriptive data for the initial data set is mostly the same when seasonally adjusted, with slight changes in value. The data for Gross Domestic Product is presented. By analyzing simultaneously, the minimum, maximum and mean parameters, it can be noted that the dependent variable has an increasing evolution. Its standard deviation is not in any way similar to the other variable's standard deviations, there is no risk of covariance.

After generating the VAR output, the results can be tested for impulse-response function equations. The resulted coefficients generated by then impulse-response equations serve as non-unitary weights for the construction of the Financial Stability Index (FSI).

\section{Table 6. VAR model output}

\begin{tabular}{|c|c|c|c|}
\hline & $\mathrm{GDP}_{\overline{\mathrm{SE}}} \mathrm{INS}$ & BET_SA & $\begin{array}{c}\text { ROBOR_3M } \\
\text { SA }\end{array}$ \\
\hline \multirow{3}{*}{ GDP__INSSE_(-1) } & 0.624456 & 0.031683 & $-6.31 \mathrm{E}-06$ \\
\hline & $(0.16115)$ & $(0.03498)$ & (4.4E-05) \\
\hline & [3.87502] & {$[0.90574]$} & {$[-0.14441]$} \\
\hline \multirow[t]{3}{*}{ GDP_IINSSE_(-2) } & 0.432752 & -0.020392 & $1.01 \mathrm{E}-05$ \\
\hline & $(0.16730)$ & $(0.03632)$ & $(4.5 \mathrm{E}-05)$ \\
\hline & [2.58668] & {$[-0.56152]$} & [0.22213] \\
\hline \multirow[t]{3}{*}{ BET_SA(-1) } & 0.558243 & 0.826309 & 1.05E-05 \\
\hline & $(0.95944)$ & $(0.20826)$ & $(0.00026)$ \\
\hline & [0.58184] & [ 3.96763] & [ 0.04023] \\
\hline \multirow[t]{3}{*}{ BET_SA(-2) } & -0.286952 & -0.181386 & $-2.45 E-05$ \\
\hline & $(0.97196)$ & $(0.21098)$ & $(0.00026)$ \\
\hline & {$[-0.29523]$} & {$[-0.85973]$} & {$[-0.09298]$} \\
\hline \multirow[t]{3}{*}{ ROBOR_3M_SA(-1) } & 139.7340 & 126.6434 & 0.874173 \\
\hline & $(680.973)$ & $(147.817)$ & $(0.18459)$ \\
\hline & [0.20520] & [0.85676] & [ 4.73570] \\
\hline \multirow[t]{3}{*}{ ROBOR_3M_SA(-2) } & -1.255528 & -155.6276 & 0.068300 \\
\hline & $(694.934)$ & $(150.848)$ & $(0.18838)$ \\
\hline & {$[-0.00181]$} & {$[-1.03169]$} & [0.36257] \\
\hline \multirow[t]{3}{*}{$\mathrm{C}$} & -7330.576 & 467.5159 & -0.477421 \\
\hline & $(3641.69)$ & $(790.493)$ & $(0.98716)$ \\
\hline & {$[-2.01296]$} & [0.59142] & {$[-0.48363]$} \\
\hline R-squared & 0.997763 & 0.914241 & 0.922226 \\
\hline
\end{tabular}




\begin{tabular}{|l|l|l|l|}
\hline Adj. R-squared & 0.997330 & 0.897643 & 0.907172 \\
\hline Sum sq. resids & $1.39 \mathrm{E}+08$ & 6556760. & 10.22505 \\
\hline S.E. equation & 2118.694 & 459.9004 & 0.574317 \\
\hline
\end{tabular}

After the VAR Model output is generated in EViews, it can be noted that model is a valid one, since the R-squared coefficient is $99,77 \%$. Each column of the table represents a different VAR equation. Basically, only the first equation, which denominates the nominal GDP variable as the dependent variable, is to be taken into account for the analysis. Each row of the output represents the independent variables of the VAR equation. The main concern of the study is not the output itself, but rather the impulse-response functions that can be derived from the information of above mentioned table.

Below, the table form of the impulse-response coefficients for the retained variables is presented, as follows:

\section{Table 7. Impulse-response coefficients for retained variables}

\begin{tabular}{|c|c|c|}
\hline Period & BET_SA & ROBOR_3M_SA \\
\hline 1 & 2.917176 & 0.020406 \\
\hline & $(74.6049)$ & $(0.09314)$ \\
\hline 2 & 72.12146 & 0.004503 \\
\hline & $(93.9281)$ & $(0.12281)$ \\
\hline
\end{tabular}

Source: Author's own calculations using EViews

Responses are received from the very first quarter of the analyzed period. These uncorrelated values represent the response of the variable nominal GDP to the impulses of each independent variable's standard deviation, from within the table.

$\mathrm{FSI}=2.917176 \times$ BET_SA $+0.020406 \times$ ROBOR_3M_SA

Otherwise, if the Principal Component Analysis would not have been applied, the table form of the impulse-response coefficients could be represented as below:

Table 8. Impulse-response coefficients for all initial variables

\begin{tabular}{|c|c|c|c|c|}
\hline Period & BET_SA & $\begin{array}{c}\text { ROBOR_3 } \\
\text { M_SA }\end{array}$ & $\begin{array}{c}\text { PRIVATE_PENSI } \\
\text { ON_FUND_SA }\end{array}$ & $\begin{array}{c}\text { INTERMEDIATE_DGRE } \\
\text { SA }\end{array}$ \\
\hline 1 & 38.99326 & 0.038922 & 0.047761 & -0.750555 \\
\hline
\end{tabular}




\begin{tabular}{|l|c|c|c|c|}
\hline & $(59.8849)$ & $(0.08010)$ & $(0.18182)$ & $(0.23661)$ \\
\hline 2 & 70.95041 & 0.095519 & 0.135718 & -0.781158 \\
\hline & $(90.8376)$ & $(0.10394)$ & $(0.28617)$ & $(0.35839)$ \\
\hline & & & & \\
\hline
\end{tabular}

Source: Author's own calculations using EViews

To be noted that the coefficient for the seasonally adjusted BET_SA is much too high in value to be considered.

$\mathrm{FSI}=38.99326 \times$ BET_SA $+0.038922 \times$ ROBOR_3M_SA $+0.047761 \times$

PRIVATE_PENSION_FUND_SA - $0.750555 \times$ INTERMEDIATE_DGRE_SA

As it stands, the result of this paper is only experimental, it alone does not hold a practical use. Its potential can be revealed when applying the same methodology for every national economy. It lacks a functional framework, without a benchmark value and interval limits, a minimum and maximum threshold.

\section{Conclusions}

The purpose of this econometric study is to offer a more reliable composite financial index, that does not rely on macroeconomic variables. Most research paper use a macro-prudential approach to determine the strengths and weaknesses of various national financial systems. By selecting more appropriate variables, that could best describe the fluctuations of money markets, capital markets, insurance markets and so on, we can create more accurate indexes that could perform a comprehensive diagnostic of a financial reality.

The scope of the Principal Component Analysis was to preselect, before integrating all data into the VAR model, the less redundant series, with no mutual correlations that could represent, as proxies, the actual market movement, without overlapping information that could only generate statistic noise. The VAR model was crucial in generating the necessary coefficients, that could serve as proportions or non-unitary weights for the composite index.

The final stage that needs to be implemented past this study, is to create an even larger database, using the same logic, with Financial Stability Indexes for each economy of the world. This index alone is not yet for practical use, but by creating a broader set of FSI variables, interval limit could be determined, and benchmark values could be set, by associating a certain value to thriving economies. Also, the index could be divided with respect to other criteria, such 
as country size, level of development, political orientation and so on. The possibilities of this type of index are virtually boundless, the only remaining concern being the need of an adequate calibration and functional framework.

\section{References}

ALBULESCU C.T. (2008). Assessing Romanian Financial Sector Stability by Means of an Aggregate Index. Oeconomica, 17(2): 67-87.

ARZAMASOV V., PENIKAS H. (2014). A Financial Stability Index for Israel. 2nd International Conference on Information Technology and Quantitative Management. ITQM 2014.

BABAR S., LATIEF R., ASHRAF S., NAWAZ S. (2019). Financial Stability Index for the Financial Sector of Pakistan. MDPI Journal Economies 2019, 7, 81.

GERŠL A., HEŘMÁNEK J. (2007). Financial Stability Indicators: Advantages and Disadvantages of their use in the Assessment of Financial System Stability. CNB 2007.

MANOLESCU C. M., MANOLESCU E. (2017). The Financial Stability Index - An Insight into the Financial and Economic Conditions of Romania. Theoretical and Applied Economics Volume XXIV (2017), No. 4(613), Winter, pp. 5-24.

MORALES M.A., ESTRADA D. (2010). A Financial Stability Index for Colombia. Annals of Finance, Springer, vol. 6(4), pages 555-581, October 2010.

MORRIS V.C. (2010). Measuring and Forecasting Financial Stability: The Composition of an Aggregate Financial Stability Index for Jamaica. Financial Stability Department Bank of Jamaica. August 2010.

STANCU I. (2017). Financial Stability Index [3] Estimated by the Institute of Financial Studies. Financial Studies Journal Vol. II No.3 November 2017.

The Financial Supervisory Authority (ASF). Insurance Market development Reports from Q1 2010 to Q4 2019.

VINTU D., NEGOTEI I-A. (2018). Analysis of Financial Stability: The Construction of a New Composite Financial Stability Index for Euro Area. „Ovidius” University Annals, Economic Sciences Series Volume XVIII, Issue $1 / 2018$. 